\title{
Lessons learned during Covid-19 from engineering asset management of dams
}

Armin Aalirezaei BSC

MASc Student, Industrial Systems Engineering, University of Regina, Regina, SK, Canada

Abdullah Alzahrany BSC

MASc Student, Industrial Systems Engineering, University of Regina, Regina, SK, Canada

\section{Golam Kabir PhD}

Assistant Professor, Industrial Systems Engineering, University of Regina, Regina, SK, Canada (corresponding author: golam.kabir@uregina.ca)

Public and private owners of critical infrastructures all over the world are taking high-quality standards to face the consequences of pandemics, particularly critical infrastructure such as dams that needs more attention to maintain and operate during coronavirus disease (Covid-19) pandemics. In this study, critical strategies have been identified through literature review and with the support of experts' opinions. The rough Decision-making Trial and Evaluation Laboratory and interpretive structural modelling methods were integrated to determine the most important strategies that were identified by literature review and experts' opinions. Moreover, the methodology was used to find the relationships, cause and effect between the critical strategies. Interviews were completed with professional managers and experts in the field of dam operation and maintenance to help in finding the influence degree between these critical strategies. Among 11 initial strategies, six critical strategies were selected for this study from the experts' points of view. By applying Matriced Impacts Croisés Multiplication Appliquée á un Classement analysis, driving and dependence powers were also determined and classified for these strategies. The outcomes indicate that the strategy of reviewing emergency action plans and planning for how routine and unplanned work will be implemented during pandemic staffing restrictions is the most driving among these strategies in dam asset management in Canada during pandemics.

\section{Notation}

$A_{n_{i}} \quad$ antecedent set

$\mathrm{D}_{i j} \quad$ direct-relation matrix

$\widetilde{\mathbf{D}}_{i j} \quad$ aggregated matrix

$\mathrm{H} \quad$ overall influence matrix

I identity matrix

$m \quad$ number of experts

$N_{i j L} \quad$ number of items comprising the lower calculation

$N_{i j U} \quad$ number of items comprising the upper calculation

$O, X, A, V$ symbols for pairwise comparison

$\mathrm{P}_{\mathrm{R}} \quad$ importance

$\mathrm{R} \quad$ reachability matrix

$\overline{\mathrm{R}} \quad$ matrix average of the rough interval

$\overline{\mathrm{R}} \quad$ normalised matrix of the average matrix

$\mathrm{R}_{\mathrm{E}} \quad$ relation

$R_{e_{i}} \quad$ reachability set

$r \quad$ aspects of the reachability matrix

$r_{t_{i j}}^{L} \quad$ lower limit of the rough interval

$r_{t_{i j}}^{U} \quad$ upper limit of the rough interval

$\widetilde{\mathbf{S}}_{r_{i}}^{L} \quad$ lower normalised matrices

$\widetilde{\mathrm{S}}_{r_{i}}^{U} \quad$ upper normalised matrices

$\mathrm{T} \quad$ total relation matrix

$x_{i j} \quad$ dimensions of lower calculation

$y_{i j} \quad$ dimensions of upper calculation

$\lambda \quad$ threshold value

\section{Introduction}

Recently, many countries went through complete or partial lockdown due to the coronavirus disease 2019 (Covid-19) pandemic. For example, many countries closed all international and domestic flights, all gymnasiums, offices that require gathering at the workplace, schools, universities and many other facilities to prevent the spread of the novel coronavirus. Infrastructure in any country is significant, particularly during the time of the pandemic, during which gathering of workers at one place is discouraged. Engineering infrastructure assets are critical for the economy, health, safety, security and well-being of any nation in the world. The systems, processes, technologies, facilities, assets, networks and services essential to security, health, safety or economy are considered to be critical infrastructure (Krebs, 2020).

In Canada, essential services are determined by federal agency partners, industry experts and state and local officials based on preserving lives, societal functioning and health (PSC, 2020b) to help assist the prioritising of activities that are connected to continue operation and immediate response (Krebs, 2020). These services are not limited to people who are working on health and safety, people who are in the front line, workers in the supply chain of goods such as food and medicine and, finally, critical infrastructure. On the other hand, the availability of workers for health and safety, critical infrastructure and goods supply chain is mandatory if they are found not affected with the disease (PSC, 2020a). However, if the job does not require their attendance, they can work remotely. During a lockdown, maintenance and operation of the critical infrastructure assets of a country become a sensitive issue that requires considerable efforts.

Engineering infrastructure assets demand continuous maintenance, regular visits to the site and physical inspection by workers. 
Engineering assets include but are not limited to dams, highways, bridges, tunnels and water supply networks (Chou and Ongkowijoyo, 2019). To maintain and operate infrastructure assets requires a team of managers, engineers, supervisors and workers. Regular maintenance of all kinds of infrastructure usually is done through a visit to the location of the asset. During the visit, inspection of the asset is carried out by workers based on the maintenance planned by engineers. However, most of the operation and maintenance of critical infrastructure depends on an on-site visit.

Dams are one of the most critical assets that require planned visits to their location (Blanco et al., 2019). The benefits of dams are crucial to society, to the economy and to the environment (HaririArdebili, 2018). Dams are one of the infrastructure assets that need continuous operation and maintenance services. Maintaining and operating dams are considered to be one of the essential services (PSC, 2020b). Krebs (2020) categorised dams to be under the public works that are essential infrastructure. He also mentioned that workers must maintain the continuity of operation and maintenance during a lockdown. Engineers and workers through the years found that dams can never be maintained and operated remotely due to possible unseen hazards (Augusto et al., 2020). Some programs and sensing devices are regularly used to obtain data on the condition of the dam remotely. Blanco et al. (2019) have been operating and maintaining 15 dams for over 30 years. The authors mentioned that maintaining and operating dams require site visits and inspection of dams on a regular basis. However, old dams differ from new ones, where new ones might not require the same amount of maintenance that old dams need. Therefore, the required maintenance is determined based on the condition rating and other factors such as age. Dams are an extremely important asset that would require more attention during pandemics. Managing dam assets during regular times is competitive work (Blanco et al., 2019). Therefore, working in the maintenance and operation of dam assets need to utilise workers' capacity at all times (Council, 2018). However, during pandemics, managing the dam engineering assets is in need of more attention due to the requirement of the availability of workers to maintain and operate dams (Krebs, 2020; Rio, 2020).

For this, the Canadian Dam Association (CDA, 2020) suggested some strategies such as reduced staffing levels with the identification of essential employees, application of remote sensing and monitoring of instruments, best use of the available technology to promote social distancing and self-isolation and redundant communication systems or methods to allow social distancing. However, it is challenging for dam owners and operators to implement all the strategies at the same time. For this, it is important to know which strategies are the most critical or effective. On the other hand, some of the strategies can affect or be related to each other. For example, the application of remote sensing and monitoring of the instruments can help reduce staffing but a new workforce might be needed who are technically capable of implementing the strategy. Similarly, if the agency wants to review its emergency action plans, then it should also review its maintenance plan to determine how routine and unplanned work will be implemented during pandemic staffing restrictions. Therefore, it is critical to examine the contextual relationships among the strategies for effective implementation.

The main objective of this study is to determine strategies that help manage the operation and maintenance of a dam during a pandemic. For the determination of the critical strategies, a decision-making framework is established in this study. This study will answer the following research questions.

- What are the most effective strategies that can be implemented during the pandemic to manage dams in the perspective of operation and maintenance?

- What are the relationships between the critical strategies that can be utilised for the operations and maintenance of dams during pandemics?

- Which strategy is a driving strategy, and which one is dependent, and what is the driving and dependence powers of these strategies?

To answer the preceding research questions, this study projected a useful method based on the integrated Decision-making Trial and Evaluation Laboratory (Dematel) and interpretive structural modelling (ISM) methods to examine the dependencies among cause-effect critical strategies of dam asset management during a pandemic. A hierarchical network model represented by a cause-effect diagram was provided, and the value order of these strategies was identified. As the assessment of the dependencies of strategies includes uncertainty due to subjective judgement of experts, the interaction between the strategies is assessed by using rough Dematel, which is the integration of crisp Dematel and rough set theory, where rough theory addresses the involvement of uncertainties and vagueness. By making use of a Matriced Impacts Croisés Multiplication Appliquée á un Classement (Micmac) assessment, strategies were clustered into four groups according to their driving and dependence values. This modelling proves relations among different strategies and augments having a clear insight on the complex and multifaceted cause-effect system (Song and Cao, 2017). Regarding mentioned strategies as the variables of the study and recognising a proper relationship between them can help managers make more reliable decisions.

The rest of this paper is arranged as follows. Section 2 describes the methodology that is used in this study. In Section 3, date analysis of a real case is written by the authors. Results and discussion are also added to Section 3. Finally, the conclusion of this paper is in Section 4.

\section{Methodology}

In this study, a hybrid method was applied to achieve a hierarchical network model delivered by a graph in a cause-effect way. This hybrid method clearly proves the joint relations among several effective strategies that can be implemented during the pandemic to manage dams in the perspective of operation and 
Smart Infrastructure and Construction

Volume 173 Issue 3
Lessons learned during Covid-19 from

engineering asset management of dams

Aalirezaei, Alzahrany and Kabir maintenance. The ambiguity and subjectivity of dam engineering assets management are often not considered. Hence, it is crucial to utilise a more effective method to assess the effective strategies under an ambiguous situation, systematically. In the present study, a rough Dematel-ISM method is presented to evaluate the critical strategies under an ambiguous situation. A flow diagram of the implementation of the Dematel-ISM method is shown in Figure 1.

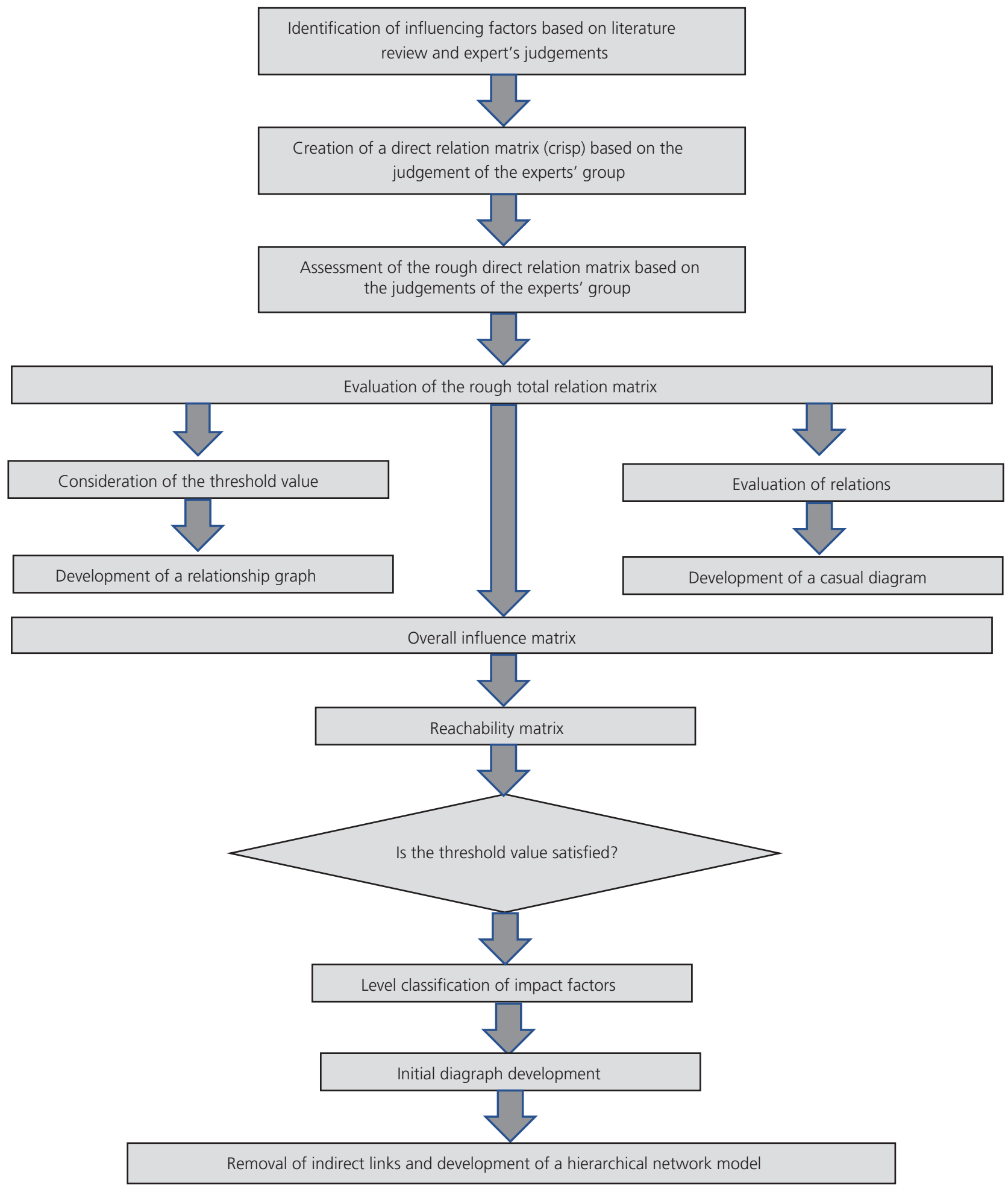

Figure 1. Flow diagram of implementation of the rough Dematel-ISM method 


\subsection{Rough Dematel method}

To decrease the ambiguity, the traditional crisp Dematel method and rough set theory are integrated. Suppose that $m$ experts are asked to define the influencing factors and to create an $m$ directrelation matrix $\left(\mathbf{\mathbf { D }}_{i j}\right)$ with the same influencing range. Equation 1 represents the matrix of the $k$ th expert.

1. $\dot{\mathbf{D}}_{i j}=\left[\begin{array}{cccc}\hat{d}_{11}^{k} & \hat{d}_{12}^{k} & \cdots & \hat{d}_{1 n}^{k} \\ \hat{d}_{21}^{k} & \hat{d}_{22}^{k} & \ldots & \dot{d}_{2 n}^{k} \\ \vdots & \vdots & \ddots & \vdots \\ \dot{d}_{n 1}^{k} & \dot{d}_{n 1}^{k} & \ldots & \dot{d}_{n n}^{k}\end{array}\right]$

Now the following steps are implemented for applying the rough Dematel approach (Liu and Ming, 2019; Pawlak, 1998).

Step 1. In this step, an aggregated matrix $\left(\widetilde{\mathbf{D}}_{i j}\right)$ of direct relation is generated based on the panel of experts. To do so, the average method is measured for the creation of the $\left(\widetilde{\mathbf{D}}_{i j}\right)$ matrix as shown in the following equation:

2. $\quad \widetilde{\mathbf{D}}_{i j}=\left[\begin{array}{cccccc}1 & \widetilde{d}_{12}^{2} & \ldots & \widetilde{d}_{1 k}^{k} & \ldots & \widetilde{d}_{1 n}^{n} \\ \widetilde{d}_{21}^{1} & 1 & \ldots & \widetilde{d}_{22}^{k} & \ldots & \widetilde{d}_{2 n}^{n} \\ \vdots & \vdots & \vdots & \vdots & \ddots & \vdots \\ \widetilde{d}_{n 1}^{1} & \widetilde{d}_{n 2}^{2} & \ldots & \widetilde{d}_{n k}^{k} & \ldots & 1\end{array}\right]$

For $m$ experts, $\widetilde{d}_{i j}$ is the dimension of $\widetilde{\mathbf{D}}_{i j}$ and $\widetilde{d}_{i j}=$ $\left(\dot{d}_{i j}^{1}, \hat{d}_{i j}^{2}, \ldots, \dot{d}_{i j}^{k}, \ldots, \dot{d}_{i j}^{m}\right)$.

Step 2. In this step, all dimensions of the $\widetilde{\mathbf{D}}_{i j}$ matrix are transformed into a rough number (RN) (Zhai et al., 2009). For calculating the lower and upper limits of $\dot{d}_{i j}^{k}$, Equation 3 is used:

$$
\underline{\dot{d}_{i j}^{k}}=\cup\{X \in U / J(X)\} \leq \dot{d}_{i j}^{k}
$$

3. and $\overline{\bar{d}_{i j}^{k}}=\cup\{X \in U / J(X)\} \geq \dot{d}_{i j}^{k}$

where $U$ and $X$ are universal and $J=\dot{d}_{i j}^{1}, \dot{d}_{i j}^{2}, \ldots, \dot{d}_{i j}^{k}, \ldots, \dot{d}_{i j}^{m}$ for $m$ experts' opinion sets. After that, the lower and upper limits for all dimensions of $\widetilde{\mathbf{D}}_{i j}$ are calculated by using Equation 4 as follows:

4

$\operatorname{Lim} \underline{\dot{d}_{i j}^{k}}=\frac{\sum_{m=1}^{i j L} x_{i j}}{N_{i j L}}$ and $\operatorname{Lim} \overline{\bar{d}_{i j}^{k}}=\frac{\sum_{m=1}^{i j L} y_{i j}}{N_{i j U}}$

$x_{i j}$ and $y_{i j}$ are the dimensions of the lower and upper calculation of $\dot{d}_{i j}^{k}$, and $N_{i j L}$ and $N_{i j U}$ represent the number of items comprising the lower and upper calculation, respectively. Next, the $\mathrm{RN}$ is obtained as shown below by using Equations 3 and 4. Equation 5 indicates the RN for $\hat{d}_{i j}^{k}$ dimensions.

5. $\operatorname{RN}\left(\widetilde{d}_{i j}\right)=\left\{\left[d_{i j}^{1 L}, d_{i j}^{1 U}\right],\left[d_{i j}^{2 L}, d_{i j}^{2 U}\right], \ldots,\left[d_{i j}^{m L}, d_{i j}^{m U}\right]\right\}$

Now the $\overline{\mathbf{R}}$ matrix can be calculated by considering the average of rough interval $\overline{\operatorname{RN}\left(\widetilde{d}_{i j}\right)}$. The $\overline{\mathbf{R}}$ matrix is shown as follows:

6. $\quad \overline{\mathbf{R}}=\left[\begin{array}{cccc}{[1,1]} & {\left[d_{12}^{-L}, d_{12}^{-U}\right]} & \cdots & {\left[d_{1 n}^{-L}, d_{1 n}^{-U}\right]} \\ {\left[d_{21}^{-L}, d_{21}^{-U}\right]} & {[1,1]} & \cdots & {\left[d_{2 n}^{-U}, d_{2 n}^{-U}\right]} \\ \vdots & \vdots & \ddots & \vdots \\ {\left[d_{n 1}^{-L}, d_{n 1}^{-U}\right]} & {\left[d_{n 2}^{-L}, d_{n 2}^{-U}\right]} & \cdots & {[1,1]}\end{array}\right]$

Step 3. The next step is to generate the normalised matrix of $\overline{\mathbf{R}}$, which is constructed as follows:

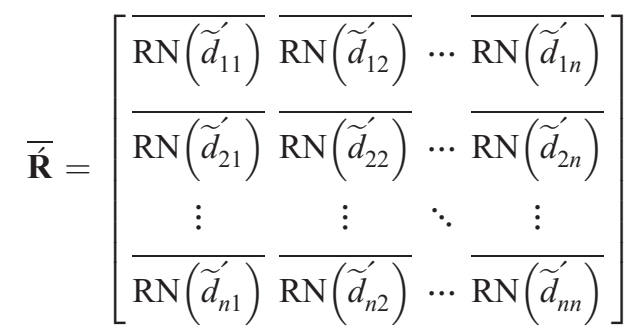

where

$$
\begin{aligned}
& \overline{\mathrm{RN}\left(\tilde{\tilde{d}}_{i j}^{\prime}\right)}=\frac{\overline{\mathrm{RN}\left(\tilde{\tilde{d}}_{i j}^{\prime}\right)}}{\tau}=\left[\frac{d_{i j}^{-L}}{\tau}, \frac{d_{i j}^{-U}}{\tau}\right] \text { and } \\
& \tau=\max _{1 \leq i \leq n} \sum_{j=1}^{n} d_{i j}^{-U}
\end{aligned}
$$

Then, for constructing $\overline{\mathbf{R}_{\mathrm{T}}}$, following equations are used:

9. $\overline{\mathbf{R}_{\mathrm{T}}}=\left[r_{t_{i j}}\right]_{n \times m}$

and

10. $r_{t_{i j}}=\left[r_{t_{i j}}^{L}, r_{t_{i j}}^{U}\right]$

and $r_{t_{i j}}^{L}$ and $r_{t_{i j}}^{U}$ are the lower and upper limits of rough interval $r_{t_{i j}}$. 
11. ${\overline{R_{T}}}^{S}=\left[r_{t_{i j}}^{S}\right]_{n \times n}=\bar{R}(I-\bar{R})^{-1} \quad$ and $\quad S=L, U$

Step 4. In this step, 'importance' $\left(\mathbf{P}_{\mathrm{R}}\right)$ and 'relation' $\left(\mathbf{R}_{\mathrm{E}}\right)$ matrices are calculated for all factors. For this, the following equations are used for calculation of summation of rows and columns and conversion to the crisp values from the $\overline{\mathbf{R}_{\mathrm{T}}}$ matrix:

12.

$$
\begin{aligned}
S_{R_{i}} & =\left[S_{r_{i}}^{L}, S_{r_{i}}^{U}\right] \\
& =\left[\sum_{j=1}^{n} S_{r_{i j}}^{L}, \sum_{j=1}^{n} S_{r_{i j}}^{U}\right] \quad \text { for summation of rows }
\end{aligned}
$$

and

13.

$$
\begin{aligned}
S_{C_{j}} & =\left[S_{c_{j}}^{L}, S_{c_{j}}^{U}\right] \\
& =\left[\sum_{i=1}^{n} r_{t_{i j}}^{L}, \sum_{i=1}^{n} r_{t_{i j}}^{U}\right]
\end{aligned}
$$

for summation of columns
15. $\mathbf{R}_{\mathrm{E}}=S_{r_{i}}-S_{c_{j}} \quad i=j$

To have a clear understating of the conversion process to the crisp value of $S_{R}$, the following equations are utilised.

16. $S_{r_{r}}=\min _{i} S_{r_{i}}^{L}+\sigma_{i} \times \Theta_{\min }^{\max }$

where

17. $\sigma_{i}=\frac{\widetilde{\mathbf{S}}_{r_{i}}^{L} \times\left(1-\widetilde{\mathbf{S}}_{r_{i}}^{L}\right)+\widetilde{\mathbf{S}}_{r_{i}}^{U} \times \widetilde{\mathbf{S}}_{r_{i}}^{U}}{\left(1-\widetilde{\mathbf{S}}_{r_{i}}^{L}+\widetilde{\mathbf{S}}_{r_{i}}^{U}\right)}$

18. $\widetilde{\mathbf{S}}_{r_{i}}^{L}=\left(S_{r_{i}}^{L}-\min _{i} S_{r_{i}}^{L}\right) / \Theta_{\min }^{\max }$

19. $\widetilde{\mathbf{S}}_{r_{i}}^{U}=\left(S_{r_{i}}^{U}-\min _{i} S_{r_{i}}^{L}\right) / \Theta_{\min }^{\max }$

20.

$\Theta_{\min }^{\max }=\max _{i} S_{r_{i}}^{U}-\min _{i} S_{r_{i}}^{L}$
Besides, $\widetilde{\mathbf{S}}_{r_{i}}^{L}$ and $\widetilde{\mathbf{S}}_{r_{i}}^{U}$ are the normalised matrices.

The $\mathbf{P}_{\mathrm{R}}$ values indicate the value of the importance of the regarded factors. A larger value of $\mathbf{P}_{\mathrm{R}}$ for a factor means greater importance/influence of that factor. $\mathbf{R}_{\mathrm{E}}$ divides the factors into two cause and effect groups. The cause group includes the positive value of $\mathbf{R}_{\mathrm{E}}$, and the effect group consists of the negative value of $\mathbf{R}_{\mathrm{E}}$. A causal graph is constructed by mapping $\mathbf{P}_{\mathrm{R}}$ and $\mathbf{R}_{\mathrm{E}}$.

Step 5. A relationship map is formed by allocating a threshold value for the rough method. The $\overline{\mathbf{R}_{\mathrm{T}}}$ matrix is transformed into a crisp value for each element by calculating the average of the lower and upper bounds. After providing the threshold value, the reachability matrix for the rough method is created using the same terms. Finally, the relationship graph is created by using the reachability matrix.

\subsection{ISM method}

ISM is a useful method that can be utilised to convert a complex system that includes directly and indirectly related elements to a wide-ranging organised model with multiple levels. Additionally, it facilitates the understanding of the driving and dependence of the considered factors. The steps for implementing the ISM method are as follows (Chowdhury et al., 2019).

Step 1. Formation of the contextual relationship between factors. A contextual relationship between factors indicates which factor will take the lead and which factor will follow among several aspects.

Step 2. Establishment of the structural self-interaction matrix (SSIM). The SSIM is like a direct-relation matrix in Dematel with a different sort of comparison. In this case, four symbols are considered for pairwise comparison: $O, X, A$ and $V$. The descriptions of these symbols are presented in Table 8 in Appendix 3.

Step 3. Construction of the initial reachability matrix. The reachability matrix $(\mathbf{R})$ is created by transforming all components of the SSIM matrix into 0 and 1 values with the rules presented in Table 9 .

Step 4. Construction of the final reachability matrix, In this step, when the reachability matrix is obtained, then the reachability set $\left(R_{e_{i}}\right)$ and antecedents set $\left(A_{n_{i}}\right)$ will be recognised based on Equations 21 and 22. After that, the levelling process is performed.

$$
R_{e_{i}}=\left\{r_{j} \mid r_{j} \in R, r_{i j}=1, j=1,2, \ldots, n\right\}
$$

21. $i=1,2, \ldots, n$

$$
A_{n_{i}}=\left\{r_{j} \mid r_{j} \in R, r_{i j}=1, j=1,2, \ldots, n\right\}
$$

22. $i=1,2, \ldots, n$

$r$ reveals the aspects of the reachability matrix. 
To make further progress in achieving the levelling of factors, for each iteration or setting of each factor, the intersection of $R_{e_{i}} \cap$ $A_{n_{i}}$ is validated. After finalising every iteration, the factors are considered the lowest level, and accordingly, the corresponding row and column are then removed from the reachability matrix. Similarly, this procedure is accomplished repeatedly until all factors are levelled accordingly.

Step 5. Generation of the relationship digraph. After placing the levels for all factors, a digraph is created with a different level and relationship between the factors.

\subsection{Integration of the Dematel-ISIM method}

In this integrated method, the total relation matrix is assessed utilising Dematel. Then, the most critical factors are discovered, and the threshold value is defined. After that, the ISM is applied to calculate the overall influence matrix, $\mathbf{H}=\mathbf{T}+\mathbf{I}$, where $\mathbf{I}$ is an identity matrix. Then, the reachability matrix $(\mathbf{R})$ is established by altering the elements of the $\mathbf{H}$ matrix with 0 and 1 . The elements of the $\mathbf{H}$ matrix is altered by 1 if the element value is greater than or equal to the threshold value $(\lambda)$ otherwise (Li et al., 2019). After that, the initial diagram is created with the different level and relationship between the factors found during the steps of the ISM method. The final diagram is obtained after removing the indirect relationship arrows.

23. $\quad r_{i j}= \begin{cases}1 & \text { if } h_{i j} \geq \lambda \quad(i=1,2, \ldots, n) \\ 0 & \text { if } h_{i j}<\lambda \quad(i=1,2, \ldots, n)\end{cases}$

\subsection{Micmac analysis}

Micmac provides a cross-effect matrix multiplication utilised for the categorisation. The purpose of the Micmac assessment is to recognise the driving and dependency values of the considered strategies. It uncovers the critical factors that push the structure in another group. Depending on the driving and dependence value of factors, they are categorised into four groups: independent, dependent, linkage and autonomous factors.

Independent factors are of a powerful strength in terms of driving, but they have weak independence power. In contrast, dependent factors provide weak driving power and strong dependence power. The factors known as linkage factors are of a strong power in terms of both driving and dependence. They are considered insecure factors, as any of their behaviours will affect other factors and produce an impact as feedback. Thus, these factors are unstable. Autonomous factors are considered weak factors in either driving and dependence power. They have a few powerful connections to the structure (Ali et al., 2020).

\section{Results and discussion}

In this part, the rough Dematel-ISM method is applied to assess the critical strategies that can be implemented during the pandemic to manage dams in the perspective of operation and maintenance in
Canada. The resilience concept can be implemented in dam asset management to boost the infrastructure of this region. In this work, the importance of each strategy is estimated by rough Dematel, so that decision makers can concentrate on the important factors to make the infrastructure more resilient during a pandemic. First, the influencing strategies for dam asset management are selected with the help of experts and literature in two phases. Secondly, the causal and relationship diagram is established by utilising the rough Dematel-ISM method.

\subsection{Selection of critical strategies}

For identification and selection of the strategies, first, several meetings are accomplished with different experts responsible for managing dams in Western Canada and review of several works of literature. The identified strategies are in general agreement with the recent guidelines outlined by the CDA (2020). Due to the confidentiality and data-sharing agreement, the names of the organisations are not mentioned. In total, 11 strategies are selected to manage dams in the perspective of operation and maintenance in Western Canada during a pandemic. The details of 11 initial strategies are provided in Table 1.

\subsection{Survey design and interviews}

After that, an initial questionnaire (Table 6 in Appendix 1) with a Likert scale was provided to obtain feedback from 11 experts to find the critical strategies with the highest ranks, among others. The Likert scale for assessing 11 strategies is provided in Table 10. It is worthwhile to mention that it was not possible to obtain feedback from more than 11 experts due to the Covid situation and restrictions. After using the weighing method (Appendix 1), Table 2 is provided as the results of the initial survey. A threshold of the top six factors with the highest weights was considered for ranking and selecting the most critical strategies for running the second stage of the assessment.

Based on Table 2, I11, I10, I7, I6, I5 and I3 are of the highest ranks among other factors. Hence, they were selected for the next stage; the final questionnaire is presented in Table 7 in Appendix 2. The critical strategies are indicated as S1, S2, ..., S6 for better representation. Eventually, a one-to-one interview was performed as the second stage to develop direct-relation matrices with three domain experts working in the field of dam safety, dam structures and design with an average work experience of more than 12 years. Their responsibilities were related to development of reservoir operating plans for all the agencyowned and agency-operated reservoirs and also taking care of the data related to the physical parameters and the operation of a reservoir under normal-, low- and high-flow conditions, to be aware of safety, security and level of maintenance and surveillance. By interviewing them, all the critical influencing factors are pairwisely compared with an influencing range 1-5, where 1 means no influence and 5 means highly influenced.

\subsection{Causal and relationship diagram}

In this process, all three experts' direct-relation matrices are combined into a single matrix (Table 3 ). 
Table 1. List of dam asset management strategies during pandemic for the initial survey

\begin{tabular}{|c|c|c|}
\hline Number & Strategy & References \\
\hline 11 & Deferred maintenance during the provincial lockdown strategy & Mattern (2018) \\
\hline 12 & Reduction of operation and maintenance level of services strategy & Su et al. (2009) \\
\hline 13 & Continued monitoring of critical instrumentation and control system on a priority basis strategy & $\begin{array}{l}\text { Public Safety Canada (PSC, 2020a, } \\
\text { 2020b), CDA (2020) }\end{array}$ \\
\hline 14 & Reduced staffing - identification of essential employee strategy & PSC (2020b), CDA (2020) \\
\hline 15 & Basic operation and maintenance training of engineers and managers strategy & Based on the experts' opinion \\
\hline 16 & Application of remote sensing and automated remote monitoring strategy & $\begin{array}{l}\text { CDA (2020), Scaioni et al. (2018), } \\
\text { Shimono et al. (2016) }\end{array}$ \\
\hline 17 & Installation of remotely operated devices strategy & $\begin{array}{l}\text { CDA (2020), Scaioni et al. (2018), } \\
\text { Shimono et al. (2016) }\end{array}$ \\
\hline 18 & $\begin{array}{l}\text { Unavailability of the operator - training backup operators and making them readily } \\
\text { available strategy }\end{array}$ & González et al. (2017) \\
\hline 19 & $\begin{array}{l}\text { Retaining/hiring a third-party or part-time worker, including engineering consultants and } \\
\text { construction workers, for additional measures that are required to be taken strategy }\end{array}$ & Beulen et al. (2005) \\
\hline 110 & $\begin{array}{l}\text { Review of the maintenance plan and planning for how routine and unplanned work will be } \\
\text { implemented during the pandemic staffing restrictions strategy }\end{array}$ & CDA (2020) \\
\hline 111 & $\begin{array}{l}\text { Review of emergency action plans and planning for how routine and unplanned work will be } \\
\text { implemented during the pandemic staffing restriction strategy }\end{array}$ & CDA (2020) \\
\hline
\end{tabular}

In accordance with Equations 3-6, the $\overline{\mathbf{R}}$ matrix is developed for six strategies (Table 11). As an example, the lower and upper bounds of $S_{1,2}=(3,2,4)$ for the $\overline{\mathbf{R}}$ matrix are calculated as follows:

$$
\begin{aligned}
& \text { upper bound of } S_{1,2}=\frac{\overline{\operatorname{Lim}(3)}+\overline{\operatorname{Lim}(2)}+\overline{\operatorname{Lim}(4)}}{11} \\
& \text { 24. }=\frac{(3+4) / 2+(3+2+4) / 3+4}{3}=3.50
\end{aligned}
$$

\begin{tabular}{|c|c|c|c|c|c|c|c|c|c|c|c|c|}
\hline \multicolumn{2}{|c|}{ Scale } & \multirow{2}{*}{$\begin{array}{r}\text { I1 } \\
0\end{array}$} & \multirow{2}{*}{$\begin{array}{r}12 \\
0\end{array}$} & \multirow{2}{*}{$\begin{array}{r}13 \\
3\end{array}$} & \multirow{2}{*}{$\begin{array}{r}14 \\
2\end{array}$} & \multirow{2}{*}{$\begin{array}{c}15 \\
7\end{array}$} & \multirow{2}{*}{$\begin{array}{r}16 \\
6\end{array}$} & \multirow{2}{*}{$\begin{array}{c}17 \\
7\end{array}$} & \multirow{2}{*}{$\begin{array}{r}18 \\
1\end{array}$} & \multirow{2}{*}{$\begin{array}{r}19 \\
0\end{array}$} & \multirow{2}{*}{$\begin{array}{r}\text { I10 } \\
5\end{array}$} & \\
\hline 5 & $\begin{array}{l}\text { Extremely } \\
\text { effective }\end{array}$ & & & & & & & & & & & \\
\hline 4 & $\begin{array}{l}\text { Somewhat } \\
\text { effective }\end{array}$ & 6 & 7 & 8 & 4 & 3 & 4 & 3 & 9 & 9 & 6 & 5 \\
\hline 3 & $\begin{array}{l}\text { Neither } \\
\text { effective nor } \\
\text { ineffective } \\
\text { (not } \\
\text { applicable) }\end{array}$ & 2 & 2 & 0 & 2 & 0 & 1 & 0 & 0 & 2 & 0 & 0 \\
\hline 2 & $\begin{array}{l}\text { Somewhat } \\
\text { ineffective }\end{array}$ & 3 & 2 & 0 & 2 & 0 & 0 & 1 & 1 & 0 & 0 & 0 \\
\hline 1 & $\begin{array}{l}\text { Extremely } \\
\text { ineffective }\end{array}$ & 0 & 0 & 0 & 0 & 0 & 0 & 0 & 0 & 0 & 0 & 0 \\
\hline & nal weight & & 38 & 47 & 36 & 47 & 49 & 49 & 43 & 42 & 49 & 50 \\
\hline
\end{tabular}

Table 2. Weights of the initial 11 strategies as the results of the initial questionnaire

Table 3. Combined matrix of all three experts' direct-relation matrices

\begin{tabular}{lcccccc} 
Strategy & S1 & S2 & S3 & S4 & S5 & S6 \\
\hline S1 & $0,0,0$ & $3,2,4$ & $3,2,4$ & $4,3,5$ & $4,3,5$ & $3,3,5$ \\
S2 & $3,2,4$ & $0,0,0$ & $4,4,5$ & $3,3,4$ & $5,5,4$ & $2,4,3$ \\
S3 & $3,2,4$ & $4,4,4$ & $0,0,0$ & $3,3,4$ & $5,4,4$ & $2,4,4$ \\
S4 & $4,3,5$ & $2,3,4$ & $3,3,4$ & $0,0,0$ & $4,2,4$ & $4,1,4$ \\
S5 & $2,3,5$ & $5,5,4$ & $5,4,3$ & $4,2,5$ & $0,0,0$ & $2,4,4$ \\
S6 & $3,3,4$ & $2,4,4$ & $2,4,4$ & $4,2,4$ & $2,4,4$ & $0,0,0$ \\
\hline
\end{tabular}

lower bound of $S_{1,2}=\frac{\operatorname{Lim}(3)}{\underline{\operatorname{Lim}(2)}+\underline{\operatorname{Lim}(4)}}$

25. $=\frac{(3+2) / 2+2+(3+2+4) / 3}{11}=2.50$

The $\overline{\mathbf{R}}$ matrix is then normalised by using Equation 7 as shown in Table 12. Next, the $\overline{\mathbf{R}_{\mathrm{T}}}$ matrix is developed by using Equations 9-11 as shown in Table 13. After obtaining the $\overline{\mathbf{R}_{\mathrm{T}}}$ matrix, the causal diagram is developed, which is shown in Figure 2.

According to Equations 16-20, the sum of rows $X_{i}$ and the sum of columns $Y_{j}$ are transformed into crisp values $\left(x_{i}\right.$ and $\left.y_{j}\right)$ to determine the prominence as $m_{i}$ and relation as $n_{i}$, which are provided in Table 14. $m_{i}$ indicates the power of influences both dispatched and received. Furthermore, if $n_{i}<0$, then the influence dispatched by strategy $i$ on other strategies is more than that it receives. If $n_{i}>0$, the influence received by strategy $i$ from other strategies is more than that it dispatches. The bold numbers in Table 14 indicate that the related strategy belongs to the effect group and it is dependent on implementation of other strategies.

On the other hand, S3, S4 and S5 have been classified as the cause group of strategies and S4 has the highest influence on others. Therefore, managers must pay a special attention to that. The final reachability matrix is shown in Table 4. The rough threshold value for critical strategies is 1.1804 , and the average $\overline{\mathbf{R}_{\mathrm{T}}}$ matrix is provided in Table 15 . Thus, based on that, the overall influence matrix is presented in Table 16 .

Finally, the level classification of impact strategies in Table 17 and the hierarchical network model (Figure 3) and Micmac analysis (Figure 4) are determined. According to the antecedent 
Smart Infrastructure and Construction Volume 173 Issue 3
Lessons learned during Covid-19 from

engineering asset management of dams

Aalirezaei, Alzahrany and Kabir

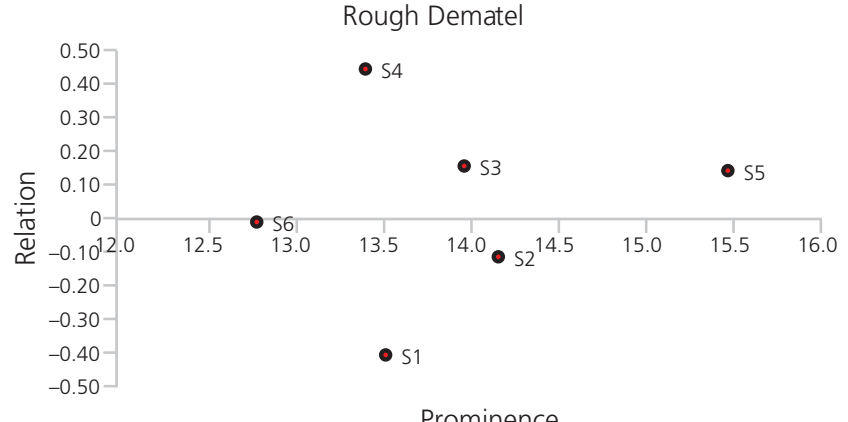

Figure 2. The casual diagram

and reachability for each strategy, the reachability matrix was divided into several dissimilar levels over iterations. The reachability set comprised the elements and other elements that were accessible. Each column that included 1 was taken into account. Likewise, the antecedent set entailed the elements and other elements that can diminish the elements. Each row that included 1 was selected. The elements that the row provided were contained in the antecedent set. Next, the elements for which the reachability and intersection sets are similar are the highest-level elements in the ISM. When the highest-level elements are discovered, these will be separated and removed from the rest of the elements. Then, again, the same repetitive procedure is done to obtained the other levels of elements.
Table 4. Final reachability matrix

$\begin{array}{lccccccc}\text { Strategy } & \text { S1 } & \text { S2 } & \text { S3 } & \text { S4 } & \text { S5 } & \text { S6 } & \text { Dependence } \\ \text { S1 } & 1 & 1 & 1 & 1 & 1 & 0 & 5 \\ \text { S2 } & 0 & 1 & 1 & 1 & 1 & 0 & 4 \\ \text { S3 } & 0 & 1 & 1 & 1 & 1 & 0 & 4 \\ \text { S4 } & 0 & 0 & 0 & 1 & 1 & 0 & 2 \\ \text { S5 } & 1 & 1 & 1 & 1 & 1 & 1 & 6 \\ \text { S6 } & 0 & 0 & 0 & 0 & 1 & 1 & 2 \\ \text { Driving } & 2 & 4 & 4 & 5 & 6 & 2 & \end{array}$

Table 5 provides a summary of the final result of the level classification of strategies.

The data shown in Tables 5 and 17 and Figure 3 demonstrate the relationships between the strategies. In level III, the strategy (S1) of reviewing emergency action plans and planning for how routine and unplanned work will be implemented during pandemic staffing restrictions is found with high driving power. This indicates that this strategy has great influence over the other five strategies and is less dependent on other factors. In level II, the strategies of (S2) application of remote sensing and automated remote monitoring and (S3) installation of remotely operated devices are found to have the same driving and dependence power. Both affect the four other different strategies, and at the same time, they also are dependent on the four different strategies. Moreover, the strategies of (S4) reviewing the maintenance plan and planning for how routine and unplanned work will be implemented during pandemic staffing restrictions, (S5) continued monitoring of critical instrumentation and

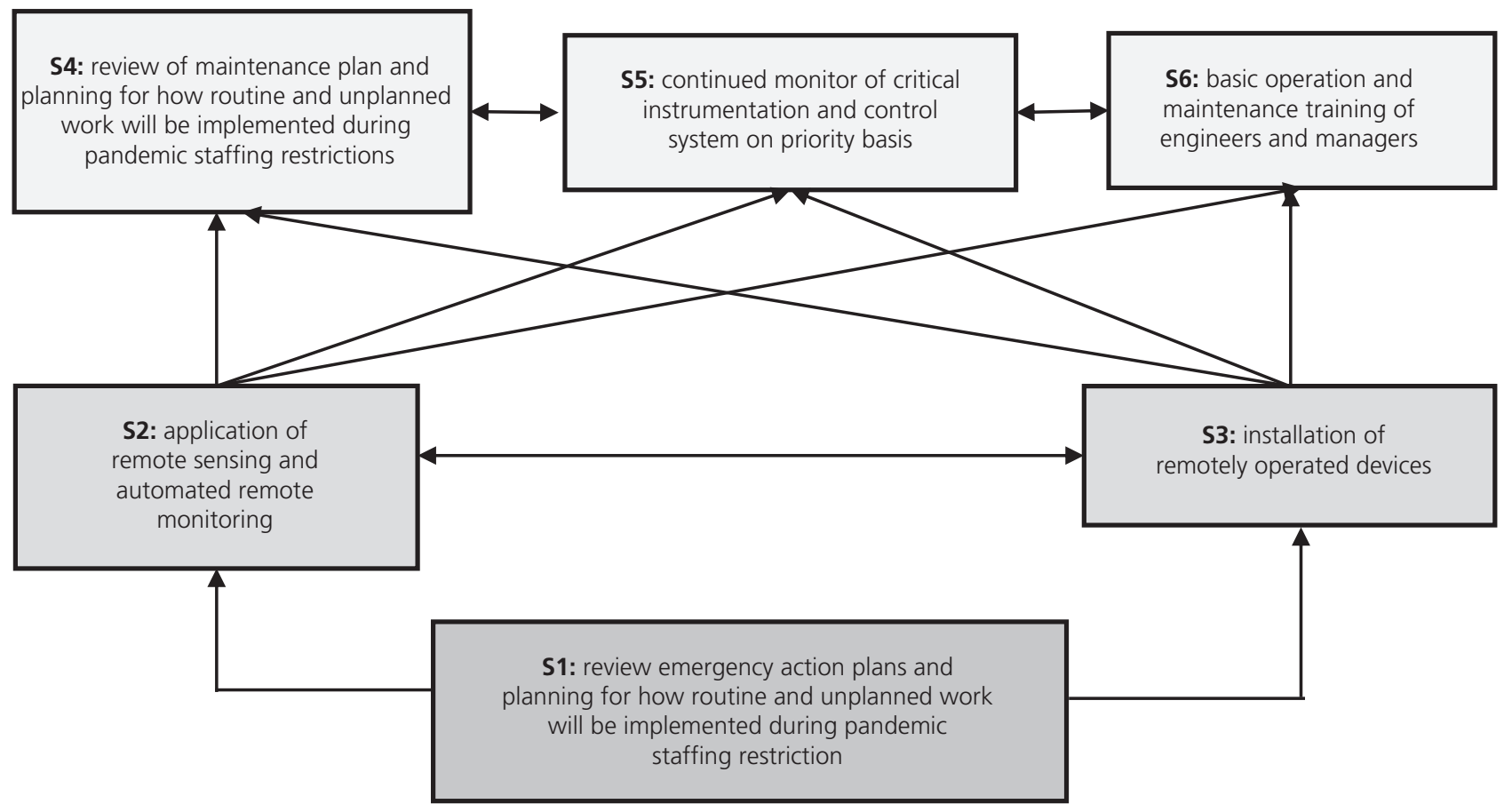

Figure 3. Hierarchical network model 


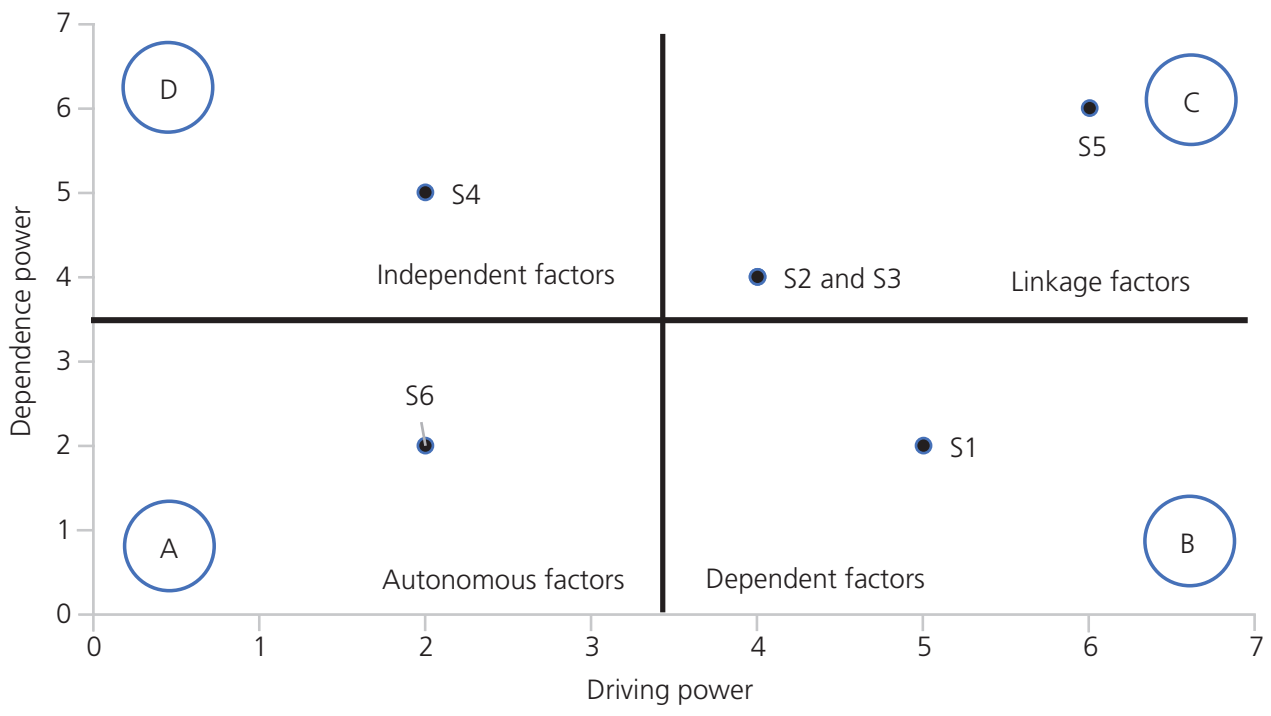

Figure 4. Micmac analysis

control system on a priority basis and (S6) basic operation and maintenance training of engineers and managers are found to be the strategies that have the least driving power.

\subsection{Results of Micmac analysis}

Micmac assessment gives useful perceptions concerning the degree of dependency that the strategies have on one another (Chowdhury et al., 2020). From this evaluation, the factors have been categorised into four groups of A (autonomous factors), $\mathrm{B}$ (dependent factors), C (linkage factors) and D (independent factors) to examine their dependency and driving powers from the perspective of the dam industry in a pandemic situation (Figure 4). It has been found that the strategy (S1) of reviewing emergency action plans and planning for how routine and unplanned work will be implemented during pandemic staffing

Table 5. Summary of level classification of strategies

\begin{tabular}{|c|c|c|}
\hline Strategy & Notation & Level \\
\hline $\begin{array}{l}\text { Review of emergency action plans and planning } \\
\text { for how routine and unplanned work will be } \\
\text { implemented during pandemic staffing } \\
\text { restrictions }\end{array}$ & S1 & III \\
\hline $\begin{array}{l}\text { Application of remote sensing and automated } \\
\text { remote monitoring }\end{array}$ & S2 & $\|$ \\
\hline Installation of remotely operated devices & S3 & $\|$ \\
\hline $\begin{array}{l}\text { Review of the maintenance plan and planning } \\
\text { for how routine and unplanned work will be } \\
\text { implemented during pandemic staffing } \\
\text { restrictions }\end{array}$ & S4 & । \\
\hline $\begin{array}{l}\text { Continued monitoring of critical } \\
\text { instrumentation and control system on a } \\
\text { priority basis }\end{array}$ & S5 & 1 \\
\hline $\begin{array}{l}\text { Basic operation and maintenance training of } \\
\text { engineers and managers }\end{array}$ & S6 & 1 \\
\hline
\end{tabular}

restrictions is going to be the independent strategy with high driving power and low dependency power (group B), which indicates that there must be a focus on this strategy to ensure success in dam asset management during pandemics.

The strategies of (S2) application of remote sensing and automated remote monitoring, (S3) installation of remotely operated devices and (S5) continued monitoring of critical instrumentation and control system on a priority basis are categorised as group $\mathrm{C}$ and recognised as connection obstacles to which administrators must give significant attention because of their high driving and dependence power. The strategy (S4) of reviewing the maintenance plan and planning for how routine and unplanned work will be implemented during pandemic staffing restrictions is found to be a dependent strategy (group D). This factor is highly dependent on other independent strategies. Therefore, the driving factors must be found to manage this one accurately. Finally, the strategy (S6) that includes basic operation and maintenance training of engineers and managers has been identified as a strategy with low dependence and driving power and classified under group A.

\section{Conclusions}

The identification of the strategies that can be implemented during pandemics is crucial to the health and safety of humanity. The main objective of this paper is to identify the most effective strategies that engineers and managers can utilise for dam asset management during a difficult time such as the Covid-19 pandemic in Canada. A hybrid decision-making method was constructed to find the most important factors among different strategies. Rough Dematel was integrated with ISM to assess and identify these critical factors. Moreover, the proposed method was used to find the contextual relationships between these factors. Then, the driving and 
dependence powers were identified through the critical strategies. The results show that the strategy of reviewing emergency action plans and planning for how routine and unplanned work will be implemented during pandemic staffing restrictions is the most driving among factors in dam asset management in Canada during pandemics. Thus, intensive planning and actions are required to prepare for pandemics such as Covid-19, and this factor must get more attention from managers to avoid any unwanted emergency situations during difficult times.

The concept of the framework used in this study can be implemented in different categories of infrastructures such as water supply networks, drainage, irrigation networks and firefighting, which are very crucial, particularly during pandemics.
Qualitative and quantitative data can be integrated by using the same framework on different influence elements of the infrastructure types. The proposed method can be a useful tool for small- to medium-sized services. It is also flexible in considering multiple contributing factors and additional information simultaneously with preferences set by the concerned powers. There were some limitations regarding this study such as the difficulty of collaboration with experts and finding a smaller number of participants due to the Covid-19 pandemic.

\section{Acknowledgement}

The third author acknowledges the financial support through the Natural Science Engineering Research Council Canada Discovery Grant Program (RGPIN-2019-04704).

\section{Appendix 1. Initial questionnaire}

Table 6. Initial questionnaire

\begin{tabular}{|c|c|c|c|c|c|}
\hline \multirow[b]{2}{*}{ Number } & \multirow[b]{2}{*}{ Strategy } & \multicolumn{4}{|c|}{ Scale } \\
\hline & & $\begin{array}{l}\text { Extremely } \\
\text { effective }\end{array}$ & $\begin{array}{l}\text { Somewhat } \\
\text { effective }\end{array}$ & $\begin{array}{l}\text { Neither effective } \\
\text { nor ineffective } \\
\text { (not applicable) }\end{array}$ & $\begin{array}{l}\text { Somewhat Extremely } \\
\text { ineffective ineffective }\end{array}$ \\
\hline 11 & $\begin{array}{l}\text { Deferred maintenance during the provincial lockdown } \\
\text { strategy }\end{array}$ & & & & \\
\hline 12 & $\begin{array}{l}\text { Reduction of operation and maintenance level of } \\
\text { services strategy }\end{array}$ & & & & \\
\hline 13 & $\begin{array}{l}\text { Continued monitoring of critical instrumentation and } \\
\text { control system on a priority basis strategy }\end{array}$ & & & & \\
\hline 14 & $\begin{array}{l}\text { Reduced staffing - identification of essential employee } \\
\text { strategy }\end{array}$ & & & & \\
\hline 15 & $\begin{array}{l}\text { Basic operation and maintenance training of engineers } \\
\text { and managers strategy }\end{array}$ & & & & \\
\hline 16 & $\begin{array}{l}\text { Application of remote sensing and automated remote } \\
\text { monitoring strategy }\end{array}$ & & & & \\
\hline 17 & Installation of remotely operated devices strategy & & & & \\
\hline 18 & $\begin{array}{l}\text { Unavailability of the operator - training backup } \\
\text { operators and making them readily available strategy }\end{array}$ & & & & \\
\hline 19 & $\begin{array}{l}\text { Retaining/hiring a third-party or part-time worker, } \\
\text { including engineering consultants and construction } \\
\text { workers, for additional measures that are required to } \\
\text { be taken strategy }\end{array}$ & & & & \\
\hline 110 & $\begin{array}{l}\text { Review of the maintenance plan and planning for how } \\
\text { routine and unplanned work will be implemented } \\
\text { during the pandemic staffing restrictions strategy }\end{array}$ & & & & \\
\hline 111 & $\begin{array}{l}\text { Review of emergency action plans and planning for } \\
\text { how routine and unplanned work will be } \\
\text { implemented during the pandemic staffing restriction } \\
\text { strategy }\end{array}$ & & & & \\
\hline
\end{tabular}




\section{Appendix 2. Final questionnaire}

Table 7. Final questionnaire

\begin{tabular}{|c|c|c|c|c|c|c|c|}
\hline Factors & & S1 & S2 & S3 & S4 & S5 & S6 \\
\hline $\begin{array}{l}\text { Review of emergency action plans and planning for how routine and unplanned work will be } \\
\text { implemented during pandemic staffing restriction }\end{array}$ & S1 & & $\begin{array}{l}\text { O EE } \\
\text { O SE } \\
\text { O NEI } \\
\text { O SI } \\
\text { O EI }\end{array}$ & $\begin{array}{l}\text { O EE } \\
\text { O SE } \\
\text { O NEI } \\
\text { O SI } \\
\text { O El }\end{array}$ & $\begin{array}{l}\text { O EE } \\
\text { O SE } \\
\text { O NEI } \\
\text { O SI } \\
\text { O EI }\end{array}$ & $\begin{array}{l}\text { O EE } \\
\text { O SE } \\
\text { O NEI } \\
\text { O SI } \\
\text { O EI }\end{array}$ & $\begin{array}{l}\text { O EE } \\
\text { OSE } \\
\text { O NEI } \\
\text { OSI } \\
\text { O EI }\end{array}$ \\
\hline Application of remote sensing and automated remote monitoring & S2 & $\begin{array}{l}\text { O EE } \\
\text { O SE } \\
\text { O NEI } \\
\text { O SI } \\
\text { O EI }\end{array}$ & & $\begin{array}{l}\text { O EE } \\
\text { O SE } \\
\text { O NEI } \\
\text { O SI } \\
O \mathrm{EI}\end{array}$ & $\begin{array}{l}\text { O EE } \\
\text { O SE } \\
\text { O NEI } \\
\text { O SI } \\
O \mathrm{EI}\end{array}$ & $\begin{array}{l}\text { O } \mathrm{EE} \\
\mathrm{O} \mathrm{SE} \\
\mathrm{O} \mathrm{NEI} \\
\mathrm{OSI} \\
\mathrm{O} \mathrm{EI}\end{array}$ & $\begin{array}{l}\text { O EE } \\
\text { O SE } \\
\text { O NEI } \\
\text { O SI } \\
\text { O EI }\end{array}$ \\
\hline Installation of remotely operated devices & S3 & $\begin{array}{l}O \mathrm{EE} \\
\text { O SE } \\
\text { O NEI } \\
\text { O SI } \\
\mathrm{O} \mathrm{EI}\end{array}$ & $\begin{array}{l}\text { O EE } \\
\text { O SE } \\
\text { O NEI } \\
\text { O SI } \\
\text { O EI }\end{array}$ & & $\begin{array}{l}\text { O EE } \\
\text { O SE } \\
\text { O NEI } \\
\text { O SI } \\
\text { O EI }\end{array}$ & $\begin{array}{l}\text { O EE } \\
\text { O SE } \\
\text { O NEI } \\
\text { O SI } \\
\text { O EI }\end{array}$ & $\begin{array}{l}\text { O EE } \\
\text { OSE } \\
\text { O NEI } \\
\text { OSI } \\
\text { O EI }\end{array}$ \\
\hline $\begin{array}{l}\text { Review of maintenance plan and planning for how routine and unplanned work will be } \\
\text { implemented during pandemic staffing restrictions }\end{array}$ & S4 & $\begin{array}{l}O \mathrm{EE} \\
\mathrm{O} \mathrm{SE} \\
\mathrm{O} \mathrm{NEI} \\
\mathrm{OSI} \\
\mathrm{O} \mathrm{EI}\end{array}$ & $\begin{array}{l}\text { O } \mathrm{EE} \\
\mathrm{O} \mathrm{SE} \\
\mathrm{O} \mathrm{NEI} \\
\mathrm{OSI} \\
\mathrm{O} \mathrm{EI}\end{array}$ & $\begin{array}{l}\text { O EE } \\
\text { O SE } \\
\text { O NEI } \\
\text { O SI } \\
O \mathrm{EI}\end{array}$ & & $\begin{array}{l}\text { O EE } \\
\text { O SE } \\
\text { O NEI } \\
\text { O SI } \\
\text { O EI }\end{array}$ & $\begin{array}{l}\text { O EE } \\
\text { O SE } \\
\text { O NEI } \\
\text { OSI } \\
\text { O EI }\end{array}$ \\
\hline Continued monitoring of critical instrumentation and control system on a priority basis & S5 & $\begin{array}{l}\text { O EE } \\
\text { O SE } \\
\text { O NEI } \\
\text { O SI } \\
\text { O EI }\end{array}$ & $\begin{array}{l}\text { O EE } \\
\text { O SE } \\
\text { O NEI } \\
\text { O SI } \\
\text { O EI }\end{array}$ & $\begin{array}{l}\text { O EE } \\
\text { O SE } \\
\text { O NEI } \\
\text { O SI } \\
\text { O EI }\end{array}$ & $\begin{array}{l}\text { O EE } \\
\text { O SE } \\
\text { O NEI } \\
\text { O SI } \\
\text { O EI }\end{array}$ & & $\begin{array}{l}\text { O EE } \\
\text { OSE } \\
\text { O NEI } \\
\text { OSI } \\
\text { O EI }\end{array}$ \\
\hline Basic operation and maintenance training of engineers and managers & S6 & $\begin{array}{l}\text { O EE } \\
\text { O SE } \\
\text { O NEI } \\
\text { O SI } \\
\text { O EI }\end{array}$ & $\begin{array}{l}\text { O EE } \\
\text { O SE } \\
\text { O NEI } \\
\text { O SI } \\
\text { O EI }\end{array}$ & $\begin{array}{l}\text { O EE } \\
\text { O SE } \\
\text { O NEI } \\
\text { O SI } \\
\text { O El }\end{array}$ & $\begin{array}{l}\text { O EE } \\
\text { O SE } \\
\text { O NEI } \\
\text { O SI } \\
\text { O EI }\end{array}$ & $\begin{array}{l}\text { O EE } \\
\text { O SE } \\
\text { O NEI } \\
\text { O SI } \\
O \mathrm{EI}\end{array}$ & \\
\hline
\end{tabular}

EE, extremely effective; El, extremely ineffective; NEl, neither effective nor ineffective (not applicable); SE, somewhat effective; SI, somewhat ineffective

\section{Appendix 3. Tables}

Table 8. Descriptions of symbols

\begin{tabular}{ll} 
Symbol in SSIM & \multicolumn{1}{c}{ Description } \\
$V$ & $i$ affects $j$ but $j$ does not affect $i$ \\
$A$ & $j$ affects $i$ but $i$ does not affect $j$ \\
$X$ & $i$ and $j$ affect in both ways \\
$O$ & Neither $i$ nor $j$ affects each other
\end{tabular}

Table 9. Rules for conversion from SSIM to reachability matrix

$\begin{array}{ccc}(\boldsymbol{i}, j) & (\boldsymbol{i}, j) & (j, i) \\ V & 1 & 0 \\ A & 0 & 1 \\ X & 1 & 1 \\ O & 0 & 0\end{array}$

Table 10. Likert scale for assessment of dam asset management strategies

\begin{tabular}{|lccccc|}
$\begin{array}{l}\text { Extremely } \\
\text { effective }\end{array}$ & $\begin{array}{c}\text { Somewhat } \\
\text { effective }\end{array}$ & $\begin{array}{c}\text { Neither effective nor ineffective } \\
\text { (not applicable) }\end{array}$ & $\begin{array}{c}\text { Somewhat } \\
\text { ineffective }\end{array}$ & $\begin{array}{c}\text { Extremely } \\
\text { ineffective }\end{array}$ \\
\hline 5 & 4 & 3 & 2 & 1 \\
\hline
\end{tabular}


Table 11. The $\overline{\mathbf{R}}$ matrix is developed for six strategies

\begin{tabular}{|c|c|c|c|c|c|c|c|}
\hline \multicolumn{2}{|c|}{ Strategy } & S1 & S2 & S3 & S4 & S5 & S6 \\
\hline \multirow[t]{2}{*}{ S1 } & L & 1 & 2.50 & 2.50 & 3.50 & 3.50 & 3.22 \\
\hline & U & 1 & 3.50 & 3.50 & 4.50 & 4.50 & 4.11 \\
\hline \multirow[t]{2}{*}{ S2 } & L & 2.50 & 1 & 4.11 & 3.11 & 4.44 & 2.50 \\
\hline & U & 3.50 & 1 & 4.56 & 3.56 & 4.89 & 3.50 \\
\hline \multirow[t]{2}{*}{ S3 } & L & 2.50 & 4 & 1 & 3.11 & 4.11 & 2.89 \\
\hline & U & 3.50 & 4 & 1 & 3.56 & 4.56 & 3.78 \\
\hline \multirow[t]{2}{*}{ S4 } & L & 3.50 & 2.50 & 3.11 & 1 & 2.89 & 2.33 \\
\hline & U & 4.50 & 3.50 & 3.56 & 1 & 3.78 & 3.67 \\
\hline \multirow[t]{2}{*}{ S5 } & L & 2.61 & 4.44 & 3.50 & 2.89 & 1 & 2.89 \\
\hline & U & 4.11 & 4.89 & 4.50 & 4.39 & 1 & 3.78 \\
\hline \multirow[t]{2}{*}{ S6 } & L & 3.11 & 2.89 & 2.89 & 2.89 & 2.89 & 1 \\
\hline & U & 3.56 & 3.78 & 3.78 & 3.78 & 3.78 & 1 \\
\hline
\end{tabular}

Table 12. Normalised rough group direct-relation matrix $(\overline{\mathbf{R}})$

$\begin{array}{llcccccc}\text { Strategy } & & \text { S1 } & \text { S2 } & \text { S3 } & \text { S4 } & \text { S5 } & \text { S6 } \\ \text { S1 } & \mathrm{L} & 0.0441 & 0.1103 & 0.1103 & 0.1544 & 0.1544 & 0.1420 \\ & \mathrm{U} & 0.0441 & 0.1544 & 0.1544 & 0.1985 & 0.1985 & 0.1813 \\ \text { S2 } & \mathrm{L} & 0.1103 & 0.0441 & 0.1813 & 0.1372 & 0.1959 & 0.1103 \\ & \mathrm{U} & 0.1544 & 0.0441 & 0.2011 & 0.1570 & 0.2157 & 0.1544 \\ \text { S3 } & \mathrm{L} & 0.1103 & 0.1764 & 0.0441 & 0.1372 & 0.1813 & 0.1275 \\ & \mathrm{U} & 0.1544 & 0.1764 & 0.0441 & 0.1570 & 0.2011 & 0.1667 \\ \text { S4 } & \mathrm{L} & 0.1544 & 0.1103 & 0.1372 & 0.0441 & 0.1275 & 0.1028 \\ & \mathrm{U} & 0.1985 & 0.1544 & 0.1570 & 0.0441 & 0.1667 & 0.1619 \\ \text { S5 } & \mathrm{L} & 0.1151 & 0.1959 & 0.1544 & 0.1275 & 0.0441 & 0.1275 \\ & \mathrm{U} & 0.1813 & 0.2157 & 0.1985 & 0.1936 & 0.0441 & 0.1667 \\ \text { S6 } & \mathrm{L} & 0.1372 & 0.1275 & 0.1275 & 0.1275 & 0.1275 & 0.0441 \\ & \mathrm{U} & 0.1570 & 0.1667 & 0.1667 & 0.1667 & 0.1667 & 0.0441\end{array}$

Table 13. Rough total-relation matrix of the strategies of dam management $\left(\overline{\mathbf{R}_{T}}\right)$

$\begin{array}{llcccccc}\text { Strategy } & & \text { S1 } & \text { S2 } & \text { S3 } & \text { S4 } & \text { S5 } & \text { S6 } \\ \text { S1 } & \mathrm{L} & 0.3540 & 0.4599 & 0.4542 & 0.4774 & 0.5208 & 0.4356 \\ & \mathrm{U} & 1.7745 & 1.9153 & 1.9301 & 1.9551 & 2.0811 & 1.8664 \\ \text { S2 } & \mathrm{L} & 0.4427 & 0.4352 & 0.5482 & 0.4936 & 0.5936 & 0.4367 \\ & \mathrm{U} & 1.8707 & 1.8151 & 1.9661 & 1.9195 & 2.0937 & 1.8427 \\ \text { S3 } & \mathrm{L} & 0.4417 & 0.5496 & 0.4256 & 0.4921 & 0.5799 & 0.4494 \\ & \mathrm{U} & 1.8244 & 1.8840 & 1.7817 & 1.8720 & 2.0311 & 1.8069 \\ \text { S4 } & \mathrm{L} & 0.4381 & 0.4433 & 0.4599 & 0.3627 & 0.4823 & 0.3884 \\ & \mathrm{U} & 1.8275 & 1.8320 & 1.8484 & 1.7382 & 1.9686 & 1.7721 \\ \text { S5 } & \mathrm{L} & 0.4408 & 0.5593 & 0.5198 & 0.4793 & 0.4538 & 0.4448 \\ & \mathrm{U} & 2.0060 & 2.0777 & 2.0812 & 2.0649 & 2.0724 & 1.9647 \\ \text { S6 } & \mathrm{L} & 0.4295 & 0.4644 & 0.4591 & 0.4456 & 0.4895 & 0.3380 \\ & \mathrm{U} & 1.7691 & 1.8163 & 1.8307 & 1.8204 & 1.9407 & 1.6412\end{array}$

Table 14. Sum of rows and columns and prominence and relation for the critical strategies

\begin{tabular}{|c|c|c|c|c|c|c|c|c|}
\hline \multirow{2}{*}{ Strategy } & \multicolumn{2}{|c|}{ Sum of rows } & \multicolumn{2}{|c|}{ Sum of columns } & \multirow{2}{*}{$x_{i}$} & \multirow{2}{*}{$y_{j}$} & \multirow{2}{*}{$m_{i}$} & \multirow{2}{*}{$n_{i}$} \\
\hline & & & & & & & & \\
\hline S1 & 2.5468 & 11.0722 & 6.5612 & 6.9652 & 6.5612 & 6.9652 & 13.5263 & -0.4040 \\
\hline S2 & 2.9117 & 11.3405 & 7.0265 & 7.1390 & 7.0265 & 7.1390 & 14.1655 & -0.1125 \\
\hline S3 & 2.8668 & 11.4382 & 7.0644 & 6.9073 & 7.0644 & 6.9073 & 13.9716 & 0.1571 \\
\hline S4 & 2.7506 & 11.3701 & 6.9286 & 6.4833 & 6.9286 & 6.4833 & 13.4119 & 0.4453 \\
\hline S5 & 3.1199 & 12.1876 & 7.8053 & 7.6618 & 7.8053 & 7.6618 & 15.4671 & 0.1435 \\
\hline S6 & 2.4929 & 10.8940 & 6.3931 & 6.4022 & 6.3931 & 6.4022 & 12.7953 & -0.0091 \\
\hline
\end{tabular}


Table 15. H matrix

$\begin{array}{lcccccc}\text { H } & \text { S1 } & \text { S2 } & \text { S3 } & \text { S4 } & \text { S5 } & \text { S6 } \\ \text { S1 } & 3.2596 & 2.3294 & 2.3590 & 2.3442 & 2.3909 & 2.2322 \\ \text { S2 } & 2.3123 & 3.3862 & 2.4010 & 2.4007 & 2.4547 & 2.2724 \\ \text { S3 } & 2.2684 & 2.3375 & 3.3638 & 2.3405 & 2.4050 & 2.2336 \\ \text { S4 } & 2.2313 & 2.2396 & 2.3285 & 3.2906 & 2.3473 & 2.1474 \\ \text { S5 } & 2.2494 & 2.3682 & 2.3733 & 2.3460 & 3.3947 & 2.1981 \\ \text { S6 } & 2.4118 & 2.4735 & 2.5052 & 2.4894 & 2.5306 & 3.2919\end{array}$

Table 16. $\overline{\mathbf{R}_{\mathrm{T}}}$ matrix

$\begin{array}{lcccccc}\mathbf{\mathbf { R } _ { \mathbf { T } }} & \mathbf{S 1} & \mathbf{S 2} & \mathbf{S 3} & \mathbf{S 4} & \mathbf{S 5} & \mathbf{S 6} \\ \mathbf{S 1} & 1.0643 & 1.1876 & 1.1921 & 1.2162 & 1.3010 & 1.1510 \\ \mathbf{S 2} & 1.1567 & 1.1252 & 1.2572 & 1.2065 & 1.3437 & 1.1397 \\ \text { S3 } & 1.1330 & 1.2168 & 1.1036 & 1.1820 & 1.3055 & 1.1281 \\ \text { S4 } & 1.1328 & 1.1376 & 1.1542 & 1.0504 & 1.2255 & 1.0802 \\ \text { S5 } & 1.2234 & 1.3185 & 1.3005 & 1.2721 & 1.2631 & 1.2047 \\ \text { S6 } & 1.0993 & 1.1404 & 1.1449 & 1.1330 & 1.2151 & 0.9896\end{array}$

Table 17. Level classification of impact strategies

\begin{tabular}{|c|c|c|c|c|c|}
\hline Iteration & Variables & Reachability set & Antecedent set & Intersection set & Level \\
\hline \multirow[t]{6}{*}{ Iteration 1} & S1 & $1,2,3,4,5$ & 1,5 & 1,5 & \\
\hline & S2 & $2,3,4,5$ & $1,2,3,5$ & $2,3,5$ & \\
\hline & S3 & $2,3,4,5$ & $1,2,3,5$ & $2,3,5$ & \\
\hline & S4 & 4,5 & $1,2,3,4,5$ & 4,5 & I \\
\hline & S5 & $1,2,3,4,5,6$ & $1,2,3,4,5,6$ & $1,2,3,4,5,6$ & I \\
\hline & S6 & 5,6 & 5,6 & 5,6 & I \\
\hline \multirow[t]{3}{*}{ Iteration 2} & S1 & $1,2,3$ & 1 & 1 & \\
\hline & S2 & 2,3 & $1,2,3$ & 2,3 & $\|$ \\
\hline & S3 & 2,3 & $1,2,3$ & 2,3 & $\|$ \\
\hline Iteration 3 & S1 & 1 & 1 & 1 & III \\
\hline
\end{tabular}

\section{REFERENCES}

Ali SM, Hossen MA, Mahtab Z et al. (2020) Barriers to lean six sigma implementation in the supply chain: an ISM model. Computers \& Industrial Engineering 149: article 106843, https://doi.org/10.1016/j. cie.2020.106843.

Augusto E, Ikhsan C and Hadiani R (2020) The assessment of physical condition of Delingan Dam in 2019 as an evaluation on dam maintenance. IOP Conference Series: Materials Science and Engineering 858(1): article 012003, https://doi.org/10.1088/1757899X/858/1/012003.

Beulen E, Van Fenema P and Currie W (2005) From application outsourcing to infrastructure management: extending the offshore outsourcing service portfolio. European Management Journal 23(2): 133-144.

Blanco A, Pardo-Bosch F, Cavalaro S and Aguado A (2019) Lessons learned about the diagnosis of pathologies in concrete dams: 30 years of research and practice. Construction and Building Materials 197: 356-368, https://doi.org/10.1016/j.conbuildmat.2018. 11.143 .

CDA (Canadian Dam Association) (2020) CDA Guidance on Dam Safety during COVID-19 Pandemic. CDA, Toronto, ON, Canada. See https:// www.cda.ca/EN/Announcements/Active/COVID-19_dam_safety.aspx (accessed 23/10/2020).

Chou JS and Ongkowijoyo CS (2019) Hybrid decision-making method for assessing interdependency and priority of critical infrastructure. International Journal of Disaster Risk Reduction 39: article 101134.
Chowdhury NA, Ali SM, Mahtab Z et al. (2019) A structural model for investigating the driving and dependence power of supply chain risks in the readymade garment industry. Journal of Retailing and Consumer Services 51: 102-113, https://doi.org/10.1016/j.jretconser.2019.05.024.

Chowdhury NA, Ali SM, Paul SK, Mahtab Z and Kabir G (2020) "A hierarchical model for critical success factors in apparel supply chain". Business Process Management Journal 26(7): 1761-1788.

Council MD (2018) Water Supply - Asset Management Plan.

González AD, Chapman A, Dueñas-Osorio L, Mesbahi M and D'Souza RM (2017) Efficient infrastructure restoration strategies using the recovery operator. Computer-aided Civil and Infrastructure Engineering 32(12): 991-1006.

Hariri-Ardebili MA (2018) Risk, Reliability, Resilience $\left(\mathrm{R}^{3}\right)$ and beyond in dam engineering: a state-of-the-art review. International Journal of Disaster Risk Reduction 31: 806-831, https://doi.org/10.1016/j.ijdrr. 2018.07.024.

Krebs CC (2020) Guidance on the Essential Critical Infrastructure Workforce: Ensuring Community and National Resilience in COVID-19 Response. Cybersecurity and Infrastructure Security Agency, Rosslyn, VA, USA. See https:/www.cisa.gov/publication/guidance-essential-critical-infrastructureworkforce (accessed 25/08/2021)

Li F, Wang W, Dubljevic S et al. (2019) Analysis on accident-causing factors of urban buried gas pipeline network by combining DEMATEL, ISM and BN methods. Journal of Loss Prevention in the Process Industries 61: 49-57. 
Liu Z and Ming X (2019) A framework with revised rough-DEMATEL to capture and evaluate requirements for smart industrial product-service system of systems. International Journal of Production Research 57(22): 7104-7122.

Mattern S (2018) Maintenance and care. Places Journal, https://doi.org/ $10.22269 / 181120$.

Pawlak Z (1998) Rough set theory and its applications to data analysis. Cybernetics and Systems 19(7): 661-688.

PSC (Public Safety Canada) (2020a) Guidance on Essential Services and Functions in Canada during the COVID-19 Pandemic. PSC, Ottawa, ON, Canada. See https:/www.publicsafety.gc.ca/cnt/ ntnl-scrt/crtcl-nfrstrctr/esf-sfe-en.aspx (accessed 25/08/2021).

PSC (2020b) National Strategy for Critical Infrastructure. PSC, Ottawa, ON, Canada. See https://www.publicsafety.gc.ca/ cnt/rsrcs/pblctns/srtg-crtcl-nfrstrctr/index-en.aspx (accessed 25/08/ 2021).

Rio R (2020) Equipment maintenance still required during the COVID-19 pandemic. ARC Blog, 2 April. See https://www.arcweb.com/blog/ equipment-maintenance-still-required-during-covid-19-pandemic (accessed 20/05/2020).

Scaioni M, Marsella M, Crosetto M, Tornatore V and Wang J (2018) Geodetic and remote-sensing sensors for dam deformation monitoring. Sensors 18(11): article 3682.

Shimono S, Toyama S and Nishizawa U (2016) Development of underwater inspection system for dam inspection: results of field tests. Proceedings of OCEANS 2016 MTS/IEEE Monterey, Monterey, CA, USA, pp. 1-4.

Song W and Cao J (2017) A rough DEMATEL-based approach for evaluating interaction between requirements of product-service system. Computers \& Industrial Engineering 110: 353-363.

Su H, Wen Z, Hu J and Wu Z (2009) Evaluation model for service life of dam based on time-varying risk probability. Science in China Series E: Technological Sciences 52(7): 1966-1973.

Zhai LY, Khoo LP and Zhong ZW (2009) Design concept evaluation in product development using rough sets and grey relation analysis. Expert Systems with Applications 36: 7072-7079, https://doi.org/10. 1016/j.eswa.2008.08.068.

\section{How can you contribute?}

To discuss this paper, please email up to 500 words to the editor at journals@ice.org.uk. Your contribution will be forwarded to the author(s) for a reply and, if considered appropriate by the editorial board, it will be published as discussion in a future issue of the journal.

Proceedings journals rely entirely on contributions from the civil engineering profession (and allied disciplines). Information about how to submit your paper online is available at www.icevirtuallibrary.com/page/authors, where you will also find detailed author guidelines. 